Artículos

\title{
RECUERDOS, HETEROTOPÍAS Y HETEROCRONÍAS. LA EXPERIENCIA CINEMATOGRÁFICA EN LA CIUDAD DE MÉXICO
}

Jerónimo Repoll

Universidad Autónoma Metropolitana, Unidad Xochimilco, México

Vicente Castellanos

Universidad Autónoma Metropolitana, Unidad Cuajimalpa, México

Maricela Portillo

Universidad Iberoamericana, México.

Philippe Meers

Universiteit Antwerpen

Autor para correspondencia: Jerónimo Repoll, email: jeronimo.repoll@gmail.com

\section{Resumen}

En el presente artículo exploramos la experiencia cinematográfica en la Ciudad de México, teniendo como referente a la oferta fílmica pero no limitándose a ella. Ampliamos la mirada, entonces, a la historia cultural y social del cine, anclada en los usos y apropiaciones. De esta manera, desde una perspectiva sociocultural, esta investigación constituye un particular estudio del público, centrado en la memoria (siempre selectiva) de los espectadores de cine. Aquí, puntualmente, retomamos las nociones de heterotopía y heterocronía que utiliza Annette Kuhn (2004) con base en las definiciones que hizo el filósofo francés Michel Foucault (1984). Al mismo tiempo, es necesario señalar que este artículo es fruto de una investigación más amplia, réplica para la Ciudad de México del proyecto "Cultura de pantalla: ideología, economía y experiencia”, desarrollado por Meers y Biltereyst en las ciudades de Gante y Amberes, Bélgica.

Palabras clave: hetereotopía, heterocronía, memoria, espectadores.

\begin{abstract}
In this paper we explore the cinematic experience in Mexico City, taking as a reference to the film offer but not limited to it. We extend the look to the cultural and social history of cinema, anchored in uses and appropriations. Thus, from a sociocultural perspective, this research study is of a specific kind of public, focusing on (the always selective) memory of moviegoers. Here, in time, we return to the notion of heterotopy and heterochrony using Annette Kuhn (2004) based on the definiGlobal Media Journal México 15(28). Enero - junio 2018. Pp. 17-37.
\end{abstract}


tions made by the French philosopher Michel Foucault (1984). At the same time, it should be noted that this article is the result of a wider investigation, replica for Mexico City "Screen Culture: ideology, economics and experience" project, developed by Meers and Biltereyst in the cities of Ghent and Antwerp, Belgium.

Keywords: heterotopy, heterochrony, memory, moviegoers.

Recibido: 26/08/2016

Aceptado: 22/05/2018

Este trabajo se deriva del proyecto "Cultura de la pantalla: entre la ideología, la economía politica y la experiencia. Un estudio del rol social de la exhibición cinematográfica y su consumo en Ciudad de México, México (1896-2010) en interacción con la modernidad y la urbanización", réplica del estudio original $^{1}$ desarrollado en las ciudades de Gan-

\footnotetext{
1 "Screen culture: between ideology, economics
} and experience. A study on the social role of film
En la capital, especialmente, el cine es mucho más que "fábrica de sueños"; es la escuela de las psicologías individuales, es la visión de lo deseable.

Carlos Monsiváis, Luneta y Galería. Atmósferas de la capital 19201959

te y Amberes, Bélgica, y antes replicado en Monterrey, México. Este proyecto sigue la misma aproximación teórico-metodológica, desde la cual se pretende realizar un inventario de las salas de cine, un análisis de contenido de la cartelera cinematográfica y el estudio del consumo cinematográfico en la ciudad de México durante el siglo XX, incluyendo finales del siglo XIX e inicio del XXI.

De las tres etapas o partes antes descritas, aquí nos enfocamos en los resultados

exhibition and film consumption in México (1895-1992) in interaction with modernity and urbanization".

Global Media Journal México 15(28). Enero - junio 2018. Pp. 17-37. 
correspondientes al estudio del consumo cinematográfico. Para ello, trabajamos desde una perspectiva cualitativa, basado en entrevistas en profundidad, mediante un cuestionario semiestructurado, a 30 hombres y mujeres de más de 60 años, correspondientes a dos clases socioeconómicas (media baja y media alta). El objetivo final del estudio es reconstruir la cultura de pantalla en la capital mexicana. Aquí discutiremos de manera puntual la experiencia social de ir al cine.

Esta investigación, además de constituir una réplica del estudio de Meers, Biltereyst y van de Vijver (2010), reconoce como antecedentes los trabajos de Staiger (1992), Kuhn (1999) y Allen (2006), entre los más destacados aportes en la corriente del "New cinema history" o nueva historia cinematográfica, la cual subraya la importancia del espacio, el lugar y la sociabilidad como rasgos constitutivos de la experiencia cinematográfica, un desplazamiento de la historia cinematográfica centrada en el análisis de las películas.

De esta manera, la investigación se enfoca desde una perspectiva sociocultural, considerando a la producción de sentido como fruto de múltiples condicionantes, tanto estructurales como subjetivos de los contextos específicos y de las situaciones en las que se establecen las interacciones con los medios, en general, y con el cine en particular. En este marco, seguimos el modelo de "consumo fílmico en contexto" (Meers et al.,
2010) que busca esbozar los mapas de ruta de las tensiones cruciales entre los intereses comerciales de la exhibición de cine contra las apropiaciones de los espectadores, las dimensiones ideológicas de los contenidos cinematográficos y las lecturas de ellos por parte de los asistentes al cine, así como las experiencias mediáticas entre lo público y lo privado.

En este caso, se busca comprender la experiencia cinematográfica en la Ciudad de México a lo largo del siglo XX, entendiendo a la ciudad como algo más que contexto y la recepción cinematográfica como algo más que consumo cultural. Es decir, el cine nos permite pensar la ciudad, tanto como esta nos permite pensar el cine. ${ }^{2}$

Explorar la memoria (que siempre supone una reconstrucción del pasado) constituye un particular estudio de recepción. Así, este es un estudio que tiene como referente la experiencia cinematográfica, conteniendo en ella la oferta fílmica, pero sin limitarse a ella. Ampliando la mirada, entonces, a

\footnotetext{
${ }^{2}$ El cine como un fenómeno multidimensional que va mucho más allá de su lógica comercial, pero que desde una lógica industrial comprende los procesos de producción, distribución, exhibición y consumo. Y que, desde una lógica sociológica, puede asumir el papel de instrumento de dominación ideológica tanto como el de subversión (denuncia) de un orden determinado; permite, desde el consumo, diferenciar las clases sociales; es fuente de entretenimiento tanto como herramienta pedagógica, formadora de ciudadanía y educadora sentimental.
} 
la historia cultural y social del cine anclada en el espectador, sus usos y apropiaciones. Un desplazamiento similar había ocurrido tiempo antes en los estudios sobre audiencias de televisión, pasando de la inferencia de la audiencia inscrita en los textos a una audiencia activa, situada económica, social, cultural e ideológicamente. ${ }^{3}$ Por otro lado, estos estudios empatan con la noción de cinevidencia, la cual se propone como una traslación del concepto de televidencia desarrollado por Orozco (1996), en el cual se reconoce que la recepción no se limita al momento de la exposición (en este caso cinematográfica) sino que es un proceso de producción social de sentido, que comprende un antes, durante y después, un proceso abierto a múltiples actualizaciones, articulando las experiencias de ir al cine en el transcurso de la vida cotidiana, lo cual puede evidenciarse a través de explorar la memoria de los espectadores (Staiger, 1992; 2000).

En esta línea, destaca el trabajo de Kuhn (1999), el cual explora la memoria de la experiencia de ir al cine en la década de 1930 en Gran Bretaña, a través de historia oral (generada a través de entrevistas en profundidad) y una encuesta postal (con una muestra auto-seleccionada) que resultó en

\footnotetext{
${ }^{3}$ Un análisis más amplio del desplazamiento del texto al contexto puede verse en Arqueología de los estudios culturales de audiencia (Repoll, 2010).
}

Global Media Journal México 15(28). Enero - junio 2018. Pp. 17-37.
186 cuestionarios devueltos. De los diversos resultados de la investigación cabe destacar que, más allá del recuerdo de algunas películas y estrellas de la década de los treinta, el recuerdo más significativo emerge en torno al entrelazamiento de la práctica de ir al cine con la vida cotidiana. Así, el ir al cine era una más de un conjunto de actividades sociales, relacionadas con las interacciones con la familia y amigos, los recorridos por la ciudad (del barrio al centro). Ir al cine, concluye Kuhn, era parte de la vida diaria, una actividad fácil, placentera, alegre y todavía recordada con cariño.

Incorporándonos en esta tradición, compartimos con Morley el interés por las “"historias íntimas' de cómo vivimos con medios tan distintos. Una cuestión importante en este sentido es cómo nuestros recuerdos personales, sobre todo de la infancia, son formulados en torno a experiencias con los medios, como los programas y los personajes emblemáticos de la televisión [o el cine]" (Morley, 2008, p. 128).

Realizar una réplica del estudio original siempre es un desafío, pero tratar de dar cuenta de la experiencia cinematográfica en la Ciudad de México acumulada a lo largo de un siglo constituye una empresa de alto riesgo. Mientras Monsiváis describe una ciudad que entre 1920 y 1960 es ya "inabarcable, al borde de la magna explosión demográfica, aun tradicionalista, ya en tratos firmes con la modernidad, nacionalista por necesidad, cos- 
mopolita según quienes sean los arquitectos" (1994, p. 7); García Canclini, para la segunda mitad del siglo XX, la describe como megalópoli, señalando que, "cuando se afirma de la ciudad de México que es varias ciudades, suele aludirse a la dificultad de abarcar su diseminación territorial, la heterogeneidad de barrios residenciales, zonas industriales y administrativas, comerciales y universitarias, antiguas y modernas" (1998, p. 19). Este, sin duda, constituye uno de los grandes desafíos en la adecuación y concreción de los objetivos del proyecto de investigación pensado originalmente no sólo en otro contexto sociocultural, sino también, desde ciudades que poco tienen que ver con una megalópolis como la Ciudad de México. Esta apuesta, sin embargo, vale la pena si consideramos con Monsiváis que

en sus más de cien años de vida, el cine latinoamericano le ha sido esencial a millones de personas que a sus imágenes, relatos y sonidos deben en buena medida sus acervos de lo real y de lo fantástico. No obstante el predominio del cine norteamericano, las variantes nacionales en América Latina han conseguido a momentos una credibilidad inmensa (2000, p. 51).

Podríamos señalar, para cerrar este primer apartado, que en esta nueva historia del cine se encuentran dos campos de estudios, aparentemente vinculados, pero no siempre coincidentes: el campo de estudios cinematográficos y el campo de la comunicación.

\section{Aproximación teórico-metodológica}

Con la finalidad de organizar la información de las entrevistas a hombres y mujeres de más de 60 años, decidimos retomar las nociones de heterotopía y heterocronía que utiliza Annette Kuhn (2004) con base en las definiciones que hizo el filósofo francés Michel Foucault (1984).

Para Foucault estos espacios y tiempos tienen una doble existencia, la física y la simbólica. ${ }^{4}$ Son espacios heterotópicos: las cárceles, los hospitales psiquiátricos y los asilos para ancianos: "los lugares que la sociedad acondiciona en sus márgenes, en las áreas vacías que la rodean, esos lugares están más bien reservados a los individuos cuyo comportamiento representa una desviación en relación a la media o a la norma exigida" (Foucault, 2008). Mientras que las heterotopías simbólicas, se superponen a los espacios

\footnotetext{
${ }^{4}$ La distinción física y simbólica es nuestra con base en los conceptos y ejemplos que ambos autores proponen en sus textos originales.
} 
físicos, así como el cine hace pasar la vida sobre una pantalla blanca, las personas desplazan y recrean espacios. Foucault hace la siguiente analogía con la cama:

es sobre esa gran cama que uno descubre el océano, puesto que allí uno nada entre las cobijas; $y$ además, esa gran cama es también el cielo, dado que es posible saltar sobre sus resortes; es el bosque, pues allí uno se esconde; es la noche, dado que uno se convierte en fantasma entre las sábanas (Foucault, 2008).

Ambas nociones se caracterizan por tener una relación entre los recuerdos de un sujeto y la manera en que discursivamente los reconstruye y actualiza. Estos recuerdos no tienen lugares ni tiempos definidos, tampoco son cronológicos o fácilmente localizables en coordenadas cartesianas, más bien se caracterizan, como afirma Kuhn, por ser recuerdos con ciertas cualidades, con ciertas texturas, de algo incompleto, pero que sí son localizables porque se tornan significativos para quien los rememora, en nuestro caso, el espectador de cine.

"Yo puedo sentir lo que sentía" (Kuhn, 2004), dice una espectadora británica de los años treinta respecto a sus primeras experiencias cinematográficas. Este sentir Global Media Journal México 15(28). Enero - junio 2018. Pp. 17-37. actualizado en el discurso de un espectador que recuerda "cómo era ir al cine" nos permite comprender a las heterotopías y heterocronías como difusas, superpuestas, contradictorias, sensibles y relevantes para estas personas. Dice Foucault que son "lugares reales fuera de todo lugar [...], concebidos en el intersticio de las palabras". Nosotros las pensamos como impugnaciones discursivas del espacio y tiempo que se vivió en relación a la sala de cine, a las películas mismas, a las negociaciones entre familia, amigos o pareja que se daban para elegir un cine y una película en el entorno geográfico de la Ciudad de México.

Kuhn (2004) afirma que la memoria cinematográfica es un subtipo de la memoria cultural, un diálogo intersubjetivo entre la experiencia individual del espectador y la experiencia colectiva al compartir los espacios y las temporalidades que propiciaron la experiencia. En esta relación, entre lugares y espacios con los recuerdos del espectador, dos categorías son importantes para ubicar una dimensión colectiva de la memoria. Esta autora las nombra como sigue: el cine en el mundo y el mundo en el cine.

El cine en el mundo refiere al papel de las películas en la vida de los espectadores (Kuhn, 2004), pero también abarca la práctica social de "ir al cine", desde la elección de la película y la sala, hasta los motivos personales o colectivos para hacerlo. Aquí la heterotopía muestra una doble dimensión: por una 
parte, la sala en sí misma como espacio heterotópico, ${ }^{5}$ un otro espacio de un espectador que durante unas horas se libera, junto con un espacio de recuerdos difusos y fragmentados que actualiza el espectador en otro espaciotiempo de su vida.

El mundo en el cine se concibe porque las películas muestran otros mundos distintos al propio. Son mundos ajenos, extraños, de los cuales el espectador aprende. Se trata de mundos construidos gracias al dispositivo tecnológico, creativo y narrativo del cine, que da lugar a los recuerdos en forma de heterotopías y heterocronías individualmente construidas por los espectadores, pero socialmente compartidas al momento de reconstruirlas en el discurso.

Los recuerdos "puestos en discurso" por los espectadores no nos hablan de lugares ni tiempos objetivos ni cronológicos, sino de la manera en que estas personas reconstruyen la experiencia social de ir al cine, se trata de poner en relieve los espacios (físicos y simbólicos) y la sociabilidad que genera esta actividad como rasgos constitutivos de la experiencia cinematográfica.

Proponemos las siguientes categorías en las que se desagregan las heterotopías y

\footnotetext{
${ }^{5}$ Foucault describe cómo un espacio cartesiano puede motivar uno heterotópico: "El cine es una gran sala rectangular al fondo de la cual se proyecta sobre una pantalla, que es un espacio bidimensional, un espacio que nuevamente es un espacio de tres dimensiones" (1984).
}

heterocronías construidas por los espectadores entrevistados. Las salas de cine las entendemos como esos lugares heterotópicos que aíslan a los espectadores del entorno de la ciudad (el cine en el mundo) y los seducen para experimentar otros mundos a través del dispositivo cinematográfico de recuerdos, atenciones y omisiones (el mundo en el cine). Por una parte, la sala en sí misma es motivo de distinción y afecto, y por otra, exhibe espacios y tiempos simbólicos en las películas que afectan las emociones y los recuerdos del espectador. De ahí que es importante saber qué recuerdan y cómo lo recuerdan; qué eligen de esa experiencia para narrarlo (memoria selectiva); qué priorizan por motivos personales o ideológicos (memoria atesorada). Asimismo, se debe indagar ese sentimiento que Kuhn (2004) refiere como elegía: una especie de lamentación por la pérdida; una nostalgia melancólica que relaciona la sala y la película con otros lugares de la ciudad y ciertos momentos de la vida de los espectadores (la niñez, la juventud, el cine de barrio, los padres, por ejemplo). Comprender lo anterior, permite una reconstrucción de los lugares y tiempos vividos, es decir, narrativas heterotópicas y heterocrónicas difusas y fragmentadas, pero altamente significativas como experiencias individuales y culturales.

Esto da lugar a que ciertas temáticas reciban un tratamiento particular por parte de los espectadores como pueden ser las relacionadas con el amor y el romance; la identidad 
individual y colectiva; las posturas ideológicas que suscita algún aspecto de la experiencia cinematográfica; el modo de leer las películas - ya sea aceptando u oponiéndose a sus argumentos- el modo en que se presentan los personajes, o sobre la verdad o la falsedad de las referencias intra y extracinematográficas.
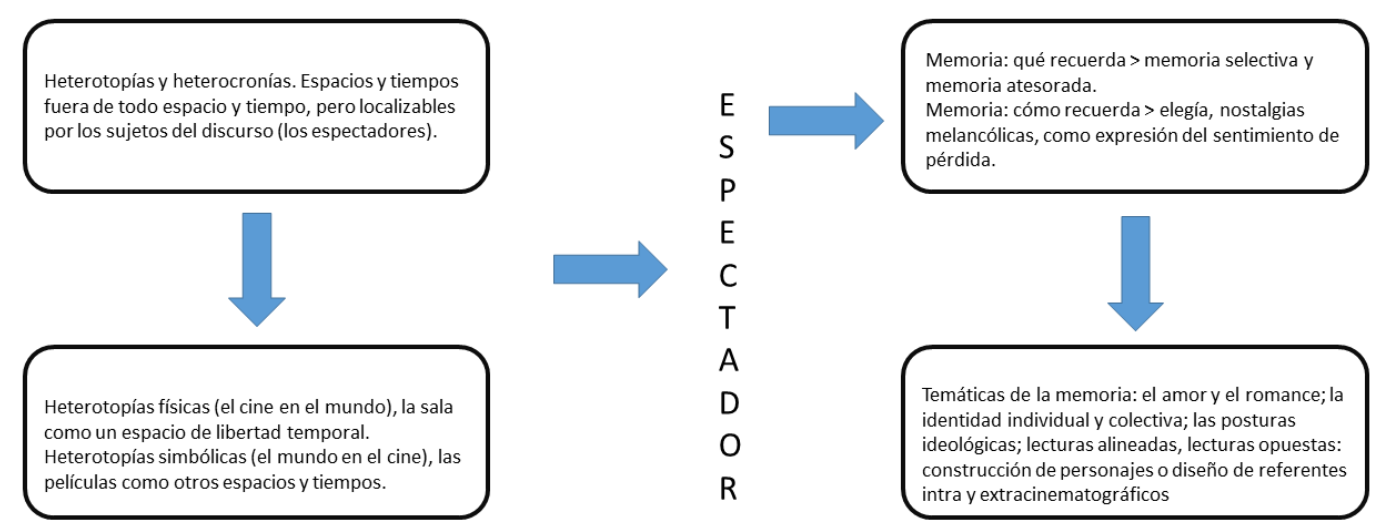

En función de lo anterior, organizamos la información de los entrevistados en el marco de las siguientes relaciones conceptuales.

1. Datos sociodemográficos: edad, clase social y género.

2. Heterotopías y heterocronías físicas con relación a la sala y la situación social de "ir al cine" en cierto en3. Heterotopías y heterocronías simbólicas para saber qué y cómo se recuerdan las películas según la memoria constatativa y referencial o atesorada en forma de elegías y nostalgias melancólicas. Esto permite conocer el papel que juega para el espectador "el mundo en el cine". torno urbano que dé información sobre "el cine en el mundo".

Global Media Journal México 15(28). Enero - junio 2018. Pp. 17-37. 
Para dar cuenta de los objetivos de la investigación, en el marco de la tradición cualitativa se realizaron 30 entrevistas a profundidad, con cuestionarios semiestructurados, a sujetos de más de 60 años, 18 mujeres y 12 hombres, la mayoría nacidos en las décadas de los treinta (dos hombres y tres mujeres) y los cuarenta (siete hombres y doce mujeres), mientras que en los extremos se ubican tres entrevistados nacidos en los veinte (dos hombres y una mujer) y tres nacidos en los cincuenta (un hombre y dos mujeres). La selección de los informantes se realizó en base del muestreo teórico, donde "lo importante es el potencial de cada caso para ayudar al investigador en el desarrollo de comprensiones teóricas sobre el área estudiada de la vida social" (Taylor \& Bogdan, 1987, p. 108). Aun no teniendo la certeza de haber llegado a la saturación de la información, es decir, de que no aparezcan testimonios con información distinta a la ya generada, la información obtenida de esta muestra permite dar cuenta de los objetivos que persigue la investigación. Siguiendo los criterios de la investigación desarrollada en Bélgica y de la cual esta es una réplica, los informantes debían cumplir con tres criterios: haber nacido en la Ciudad de México o haber llegado a vivir a ella antes de los seis años, tener más de 60 años y haber sido espectadores de cine, cinéticos o no. De esta manera podríamos acceder a diferentes tipos de espectadores. El contacto con los primeros informantes se realizó a través de nuestros estudiantes de licenciatura, aprovechando que las características socioeconómicas y culturales de la Universidad Iberoamericana (privada) y la Universidad Autónoma Metropolitana (pública) nos permitía acceder a una diversidad de informantes situados en estratos medios-altos y medios-bajos, correspondientemente. A partir de los primeros entrevistados pudimos contactar con otros entrevistados siguiendo la estrategia de la bola de nieve. Las entrevistas tuvieron una duración de entre una y dos horas y se realizaron en los domicilios de los entrevistados entre septiembre de 2016 y mayo de 2017. El cuestionario contempló tres etapas de la vida de los entrevistados: infancia, juventud y vida adulta.

En este trabajo presentamos el análisis de la generación que vivió su juventud entre las décadas de 1950 y 1960, entendiendo con Rosas Mantecón (2017) que

el crecimiento de los espectadores se dio a la par de la expansión de la urbe y la llegada masiva de migrantes. Cine y ciudad se constituyen en emblemas de la modernidad y en espacios de inclusión [...] La edad de oro del cine mexicano lo fue también de las salas, de los públicos y de la Ciudad de México (Mantecón, 2017, p. 122). 
Exploramos en el relato de nuestros informantes, a través de la memoria, la experiencia del ser joven con relación al consumo cinematográfico. Entendemos a las generaciones no como estructuras compactas, sino como "referentes simbólicos que identifican vagamente a los agentes socializados en unas mismas coordenadas temporales" (Portillo et al., 2012, p. 140). La generación estaría caracterizada, según Ortega y Gaset (1970), por sujetos que comparten cierto rango de edad y un cierto contacto vital. Los contextos juegan un rol esencial en la forma en que las generaciones desarrollan una cierta sensibilidad, una visión del mundo, una ética y cierta estética; son esos

lugares en donde se ubican juventudes tan diversas y desiguales que las coordenadas temporales que hacen a las generaciones se construyen desde las limitaciones estructurales a las que se enfrentan cotidianamente, a las que mixturan con historias más locales o más inmediatas y con elementos simbólicos de la cultura mundializada con los que sienten ciertas identificaciones como jóvenes (Portillo et al., 2012, p. 169).

Un buen ejemplo de cómo las culturas juveniles expresan estas tensiones globales/locales en sus apropiaciones mediáticas, es el consumo cinematográfico.

\section{Recuerdos de "ir al cine". "El cine en el mundo"... de los espectadores}

La infancia y la juventud de los entrevistados se ubica entre los años cuarenta y cincuenta en el contexto de una Ciudad de México que, además de ser la capital del país, se caracterizaba por su proceso de modernización con cierto aire cosmopolita y, resultado de los logros visibles de la Revolución de 1910, en la constitución de una clase media urbana y con mayores niveles de estudio. "Ir al cine" era, entre otras cosas, un acto de modernidad citadino.

Las salas de cine, como en otras grandes ciudades, estaban repartidas a lo largo del territorio urbano, con la única distinción que entre los cines del centro de la Ciudad de México y los de las colonias o barrios, era que los primeros eran majestuosos y elegantes. Así lo atestigua Gabriela Campero (76 años, clase media alta):

Las salas eran hermosas, había la luneta y el anfiteatro siempre, entonces eran cines espléndidos que se hacían para muchas personas, 1000, 800, eran cines enormes. Muy elegantes, todos tenían un gran lobby, tenían butacas buenas, y había de todo. p. 17-37. 
Por ejemplo, el cine Alameda figuraba una calle Taxqueña como la ciudad de Taxco y el cielo tenía estrellas y pasaba nubes. Tenía balconcitos y ventanas como si estuviera uno en una calle. El Palacio Chino era todo chino, hasta la taquilla era china, llamaba la atención. En el Chapultepec el lobby era bellísimo, tenía unas figuras enormes. Eran cines hechos para gustar, con un diseño arquitectónico y con un deseo de perdurabilidad que no tienen ahora. Las salas ahora parecen caballerizas (risas). El ir al cine era un acontecimiento social, se planeaba, se entraba a un espacio específico, tenía todo un ambiente que digamos de asistencia al cine que se ha perdido, ahora es una cosa inmediata y muy despojado.

Grandes salas, como el Cine Alameda, algunos con diseños “exóticos”, como El Palacio Chino, otros ubicados en la avenida más bonita de la ciudad, como El Roble, o bien, aquellos donde sólo pasaban buenas películas, como El Latino, hacían sentir que ir al cine era un acto de modernidad enmarcado en una serie de decisiones con la familia, los amigos y la pareja. Los cines de la barriada eran más frecuentados, más cercanos a las personas, porque ahí podían ver varias películas por una sola entrada y siempre quedaban a la vuelta de la casa.

Mira, mis cines, bueno yo les digo mis cines porque eran los que me quedaban en mi barrio. Te podría decir un cine de Tacuba o de la Escandón o de cualquier otra colonia. Eran mis cines porque estaban ubicados dentro de la colonia Morelos o dentro de la zona centro. Pero todos ellos tenían una magia especial. Para mí la magia del cine, en aquel tiempo empezaba por... Dando las cuatro empezaban a apagarse las luces y cada cine por muy modesto que fuera alrededor de la pantalla tenía, yo la llamo marquesina de luces de colores. Tenía también su cortina... Actualmente llegas a un cine y está la pantallota así sin nada... Estos tenían su cortina y dando las cuatro empezaban a apagarse las luces pero era una magia porque se iban apagando poco a poco, si la marquesina tenía cuatro colores o cinco colores se iban apagando un color, luego otro y luego otro. Enton- 
ces era una cosa increíble (Jorge Trejo, 82 años, clase media).

Este recuerdo nostálgico, sin embargo, no oculta las notables diferencias. Así lo reconoce Julia Landeros (clase baja, 72 años) "Pues sí, había diferencia claro, en los cines del barrio, por ejemplo: el Sonora era muy popular, y ahí iba mucha gente que trabaja en La Merced, en el mercado de Sonora, y acá, en el de Metropolitan, era de más cache". Unas diferencias que, por otra parte, no solo se establecían entre los cines del centro (los palacios) y los cines de barrio, sino en la ubicación dentro de la misma sala, entre galería y luneta. Así lo rememora Luis Ebrad (94 años, clase media):

En Coyoacán tuvimos dos cines muy buenos a partir de los años veinte, el primero fue el cine del Centenario que te dije que habían construido mis tíos, los hermanos de mi mamá, y ese cine se llamó del Centenario porque se inauguró en 1921, cuando se conmemoró el centenario de la consumación de la independencia durante la presidencia del general Obregón. Y con el tiempo vino el cine Esperanza, que está aquí a espaldas de donde me encuentro (plaza central de Coyoacán). El Esperanza era para la gente que podía pagar cinco centavos por la entrada, cinco centavitos, estaban las lunetas y estaba el anfiteatro, pero había gente del campo, bueno, gente sencilla de los barrios y de los pueblos que no tenían cinco centavos para pagar, entonces pagaban dos centavos y se subían a lo que llamaban galería, que era el tercer piso y ahí eran asientos durísimos que eran bancas nada más, el piso era de cemento, y había que subir por escaleras.

Por su parte, Gloria Escartegui (clase media, 80 años) recuerda que "íbamos a luneta pero los de galería nos aventaban cigarros y... así era... y no nos podíamos ir muy adelante porque se veía muy feo, nos teníamos que ir más o menos más para atrás para que se viera bien, porque si nos íbamos para adelante se veían feas las pantallas".

Los cines no tenían un diseño estándar como los actuales múltiplex, por el contrario, para los entrevistados era muy importante reconocer las particularidades de cada uno, sea por la arquitectura, el tipo de butaca o por el tamaño de la pantalla. Pero también las particularidades estaban relacionadas con la experiencia subjetiva de cada uno de estos espectadores para quienes el cine representaba un momento "gustoso", de gran expectatiio 2018. Pp. 17-37. 
va, una salida "emocionante", un hecho fuera de la cotidianidad y un divertimento compartido. En suma, "el cine en el mundo" era un acontecimiento que emocionaba, creaba expectativas por la película y se vivía la sala de cine como un espacio particular o de distinción.

No obstante, ninguno de los entrevistados consideró que la película o los actores tuvieran alguna influencia en su vida, más allá de una mujer que se mandó a hacer un vestido igual a la de una actriz (Rosa Cecilia Rodríguez, clase alta, 75 años); testimonio que contrasta con el de un espectador que no se vio influenciado por la moda de Tarzán (Benjamín González, clase baja, 70 años), a pesar de ser su actor favorito.

Incluso, como señala Luis Manuel Cabrera (clase media, 89 años), las películas eran lo de menos: "No, nada más era de que vamos al cine y ya, no elegíamos las películas, íbamos y veíamos las películas que estaban antes, pero no había una elección, eso fue de más grande. Antes nada más nos íbamos por gusto".

Una espectadora nos parece que resume muy bien ese espíritu de generación pues hace una distinción muy clara entre realidad y fantasía: "Veía a los actores no como ejemplos a seguir, sino algo fantástico, especial. No eran modelos a seguir" (Ana Cecilia Fuentes, clase alta, 77 años). Las películas como divertimento estaban en el plano de lo fantástico, de realidades muy ajenas a la de estos espectadores, y ahí es donde radicaba su fuerza emotiva, es decir, en no parecerse a sus vidas $y$, por tanto, no ser modelos a seguir.

Las películas, como era de esperarse, durante la infancia las elegían el padre o la madre. En la juventud, la elección llevaba consigo un proceso de negociación sobre todo entre parientes y amigos, pero no así con la pareja, pues quien decidía era el varón, quien además pagaba la entrada. En la edad adulta, las negociaciones de elección y pago de entrada dependen de la(s) persona(s) con quien(es) se asista al cine, si es con los hijos ya adultos, son estos quienes deciden y pagan, si es con los hijos que todavía son pequeños, decidían las personas entrevistadas. $\mathrm{Si}$ es con amigos, "entre todos", si es con la pareja, es el varón quien continúa decidiendo.

Sobre otras experiencias de ver películas en recintos alternos como el autocinema o la Cineteca Nacional, son prácticamente nulos durante la infancia y la juventud. Lo que sí refieren de manera constante son funciones al aire libre que se organizaban en parques y espacios públicos, por parte "del gobierno" o "por algún partido político": “6 “al aire libre sí, cuando andan los de los partidos

\footnotetext{
${ }^{6}$ Hay que aclarar que la cultura política mexicana se caracterizaba por la ambigüedad entre el partido gobernante y el gobierno en turno debido a la hegemonía de más de sesenta años en el poder del Partido Revolucionario Institucional.
} 
que ponen una manta y allí proyectan alguna película en la calle" (Guadalupe Carreño, clase baja, 66 años).

Los entrevistados en la edad adulta en su mayoría dejan de frecuentar las salas para ver cine porque son ruidosas o porque es muy caro o porque se cansan y no pueden desplazarse por ellos mismos. Los más cinéfilos, no obstante, continúan considerando al cine importante para ellos y abren sus posibilidades de consumo alternativo a la Cineteca Nacional.

Con relación a las películas, es notorio en los entrevistados la influencia del cine mexicano de la llamada época de oro. Actores y actrices, más que directores y películas, son para estas personas referentes importantes en cada etapa de su vida. Pedro Infante, Jorge Negrete, María Félix, y muchos más, son personas que a lo largo del tiempo no se pueden separar ya de sus personajes de la pantalla.

No obstante, para las personas con mayor nivel socioeconómico y estudios, el cine nacional competía con la oferta internacional en cuanto a gustos y selección, por ejemplo, con "Lo que el viento se llevó" (Fleming, Estados Unidos, 1939) y las películas provenientes de Europa. $\mathrm{Y}$ en torno al consumo o no de cine mexicano se erigía una marcada diferenciación social. De esto dan cuenta los testimonios de la clase media alta, a diferencia de la clase media baja y baja:
[El cine mexicano] tenía muy mala fama, por ejemplo: los borrachasos de Jorge Negrete, decían que eso era el ídolo de las sirvientas, eso se decía mucho (risas) tenían mucho su fotografía en sus cuartos. No pues mexicanas casi no se veían, porque decían que eran de muy mala calidad y había mucho de malos consejos y todo, no dejaban de tener cierta razón ¿eh? En aquel entonces, yo no sé que valores eran, de ser muy macho, bebiéndose el tequila porque lo traicionó la fulana y puras idioteces de esas que siguen estando vigentes. (Elba Durán, 72 años, clase media alta). Testimonio que se complementa con el de Gabriela Campero: "Mi mamá era una persona del siglo XIX (risas) donde toda su mirada estética y cultural era muy europeizada, entonces el cine mexicano le parecía, así como de rancheritos y de mariachis y eso no le gustaba" (76 años, clase media alta).

Destaca entre los entrevistados que antes o después de asistir al cine, prácticamente no se planeaba alguna actividad complementaria o se tenía una especie de ritual como cenar o Global Media Journal México 15(28). Enero - junio 2018. Pp. 17-37. 
caminar. Se llegaba a hacer, pero no era una constante o los planes cambiaban según las circunstancias.

Una de estas particularidades, es narrada por Magda Fresán (clase media, 74 años) con gran elocuencia representativa de muchas familias numerosas de clase media en la Ciudad de México, pues ir al cine también implicaba ir a "comer tortas" mientras se veía la película.

En los intermedios, los entrevistados relatan muchas actividades, desde darse una vuelta para "ver a las chamacas" hasta comentar las películas, o bien, ir a la dulcería o seguir comiendo tortas. Los entrevistados que asistían con más frecuencia al cine también eran los que más comentaban las películas durante el intermedio y al salir de la sala. Los comentarios de estos espectadores tienen rasgos de cierto criterio cinematográfico en cuanto a actuación y producción, pero sobre todo, respecto al argumento narrativo que les dejara “algo" para reflexionar. Al respecto una entrevistada afirma que durante su infancia y juventud no tenía capacidad de criticar películas, pero en la adultez sabe que ciertas pelícu- las "se azotan", y se cuestiona de dónde sacan tanta exageración (Andrea González, clase baja, 73 años).

Asimismo, esta generación de espectadores fue testigo de cómo los cines de barrio y del centro fueron desapareciendo, sea porque se abandonaron, se convirtieron en otra cosa o porque se pauperizaron para pasar de ser cines majestuosos y familiares a salas de pornografía o de películas de mala calidad. Para ellos, las salas actuales de los múltiplex son parecidas y de buena calidad, aunque ruidosas. Ahora prefieren ir a los múltiplex más cercanos a su casa porque les cuesta trabajo moverse, porque el taxi es caro o porque se cansan demasiado.

\section{Recuerdos que propició el cine. "El mundo del cine"... en la memoria del espectador}

Si bien para estos espectadores el cine representa una experiencia emotiva y significativa, sus heterotopías y heterocronías más frecuentes se relacionan con lo referencial y constatativo y no tanto con las elegías y las nostalgias. Son espectadores que la experiencia la racionalizan a partir de la concepción que tienen del entorno inmediato y no tanto por una experiencia artística, idealizada y aislada de la cotidianidad. Ven al cine como un continuum de la vida y no un momento de pausa y revelación del mundo.

Global Media Journal México 15(28). Enero - junio 2018. Pp. 17-37. 
Los recuerdos son propios de una generación que vive constantes cambios sociales en una ciudad pujante y en expansión. Esta generación marca diferencias, a veces en los márgenes de la transgresión cultural, con sus padres y abuelos. La Ciudad de México es el escenario donde todo es posible, incluso es el lugar para asistir a un espectáculo que seduce a cualquier clase social. El cine forma parte de esa nueva forma de estar y vivir la ciudad, de saberse parte de una sociedad planetaria porque las películas tienen orígenes geográficos diferentes y muestran, cual ventana abierta al mundo, rostros, cuerpos, comportamientos y paisajes ajenos, provenientes de "otros lados".

A la vez, existe una valoración positiva de la Ciudad de México en la época de su infancia y juventud, un lugar donde se podía vivir, todo era más barato, la gente más educada y se caminaba en cualquier momento del día. El costo del boleto era muy accesible y aunque la frecuencia al cine no fuera tan recurrente, cuando se iba, se iba en grupos de amigos o familia.

En este sentido, los espectadores entrevistados recuerdan una serie de sucesos, de escenas y personajes en el marco de la construcción cultural de su propia identidad como sujetos y grupo social. También se ven identificados con cierta forma de pensar, esta sí conservadora, sobre aspectos políticos y religiosos que, en el marco de la ideología dominante mexicana, es preferible no hablar Global Media Journal México 15(28). Enero - junio 2018. Pp. 17-37. ni discutir temas delicados y poco comprendidos acerca de lo público y lo religioso, pues sólo existen expresiones singulares en ambos casos: el PRI y la religión católica. Por eso, los entrevistados no muestran ningún compromiso contundente acerca de la censura o de la intervención de estos poderes en la elección de una película, pero sí expresan claramente que preferían "las películas sanas, que tuvieran algún mensaje" (María del Carmen Sánchez, clase media, 85 años); o bien, manejarse bajo cierto principio prescriptivo: "el cine es para distraerse de manera sana" (Andrea González, clase baja, 73 años).

Los casos de censura o controversia se dieron cuando las películas mostraban cierto grado de "pornografía", o bien, se criticaba al gobierno, principalmente, por la masacre del 2 de octubre de 1968 en la Plaza de la Tres Culturas de Tlatelolco, hecho que marcó el despertar político de muchos habitantes de la Ciudad de México. Al respecto, Sergio Fernández (clase media alta, 70 años) recuerda la controversia generada por $L a$ sombra del caudillo (1960) dirigida por Julio Bracho y basada en la obra homónima de Martín Luis Guzmán, en la cual se criticaba la forma de sucesión presidencial establecida por el PRI.

Por otra parte, dos entrevistadas hacen referencia a un cine en la calle de Frontera de la Colonia Roma que era propiedad de los jesuitas y en el que se iba la luz cada vez que aparecía un beso en la pantalla (Ana Ma- 
ría Espinoza, clase alta, 81 años). Y aún más preciso es el recuerdo de Elba Durán (clase media alta, 72 años):

yo me recuerdo que cuando ya estaba uno jovencito; no me recuerdo el nombre del cura que puso el club 'Vanguardias' que estaba en la colonia Condesa, Roma, saliendo de Condesa, en la calle Frontera. Y en el club 'Vanguardias' cada sábado, cada domingo el cura recibía a todos los jovencitos y pasaba las películas, pero cada vez que había un beso ponía el sombrero para que no viéramos (emocionada) (risas), entonces él censuraba lo que no deberíamos ver, $y$ era muy divertido porque todos gritábamos ¡Ah! (Grito) (risas), pero nunca nos hizo caso, él censuraba todo lo que había que censurar.

Esta experiencia de censura es representativa de un grupo de espectadores de clase media alta. Y hacen referencia a la Liga de la decencia. Al respecto, la misma Elba Durán (clase media alta, 72 años) describe su funcionamiento:

Ah bueno había la Liga de la decencia, que entiendo todavía por ahí anda perdida, pero bueno. La Liga de la decencia emitía semanalmente sus listas: $a, b, c y d$; para nosotros nomas el "a” podía ir y entonces regía la listita de la Liga de la decencia, y las repartían en la misa, y o, pues íbamos a misa cada ocho días, desde luego que sí; y ahí nos decían a dónde, y las familias seguían a la Liga de la decencia. Entonces nomas era

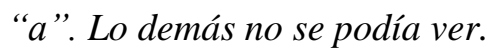

Aun sin nombrar al cine de la calle Frontera, Gabriela Campero (76, clase media alta) también recuerda la censura religiosa:

La iglesia publicaba una hojita que nos daban donde ponían $A$, $B, C$ y fuera de clasificación por inmoral. Le daban a uno esa lista de películas en la escuela y claro las de A eran las de Bambi, las de B no sé cuánto y luego las de C y las de fuera de clasificación por inmoral, ya digamos si uno veía de $C$ en adelante, era una cuestión que casi había que confesar, era falta. Se entregaba en la escuela una lista de la clasificación de las películas. Uno no encontraba muchas veces por qué había sido vetada por el cri- 
terio del episcopado o no sé quién sería el que decidía esas cosas, el Movimiento Familiar Cristiano o la Unión Cristiana de Padres de Familia.

Lo que es común es el recuerdo positivo que expresan al haber visto alguna versión de las innumerables que hay sobre la vida de Jesucristo. Sólo particularizan en el caso de la película Marcelino, pan y vino (Vajda, España, 1955), que igualmente les resulta emotiva y aleccionadora.

Las elegías o las melancolías, es decir, los recuerdos más intensos de estos espectadores son claros en las personas con más estudios, mayor nivel socioeconómico y gusto por el cine. El detalle y la precisión del recuerdo aumentan, así como la emotividad con la que narran la escena o el personaje que les hizo sentir tal emoción. Exponemos dos casos, pues son ejemplares de heterotopías y heterocronías altamente sensibles y relevantes para los espectadores entrevistados al sacarlos de lo cotidiano o al revelarles momentos críticos en las relaciones que tienen con otras personas. Magda Fresán (clase media, 74 años), por ejemplo, vio dos veces la película Shine (Hicks, Australia, 1996), porque no podía respirar y la hacía llorar tanto que se tuvo que salir de la sala. Le recordaba situaciones particulares con uno de sus hijos.

En el lado opuesto de las emociones, Rosa Cecilia Rodríguez (clase alta, 75 años), Global Media Journal México 15(28). Enero - junio 2018. Pp. 17-37. relata cómo Superman le impresionaba, pero le parecía muy cuadrado y prefería a Tarzán por sus músculos, muslos y cara. También le impresionó El fantasma de Canterville (Dazin, Estados Unidos, 1944) tanto que despertó en la noche por una pesadilla.

Por supuesto que la mayoría guarda recuerdos intensos del cine mexicano y la referencia de la muerte de "El torito", el hijo pequeño de Pepe "El Toro" en Ustedes los Ricos (Rodríguez, México, 1948), no podía faltar (Guadalupe Carreño, clase baja, 66 años). A la fuerza de la secuencia sobre un niño muerto quemado, se le agrega la educación sentimental melodramática que tanto difundió el cine nacional en la década de los cuarenta.

En el mismo sentido podemos citar el testimonio de Georgina Lomelí (clase baja, 76 años), quien reconoce en la pantalla (Nosotros los pobres / Ustedes los ricos) sus condiciones de vida:

para mí el cine, y lo que primero que vi (que fue muy impactante), esa forma (ahora ya con la experiencia que tengo y todo) esa forma de ver cómo presentan esas películas, con dos niños que sacan un libro de la basura, así era nuestra vida. $Y$ así como se ve en esa película, eso era lo que se vivía, al menos en donde nosotros vivíamos, era lo que se 
veía: esa pobreza, que el carpintero, el que era el riquillo, el que era el malo, la que se dormía de día, todo eso lo vivíamos en vivo nosotros, muy parecido, entonces, para mí fue como retratar en el cine lo que estábamos nosotros viendo, viviendo. Fuе тиу parecido. Y luego cuando entro a trabajar... bueno, yo me quedé con hambre de ver mucho cine, la verdad. Sí, yo quería ir muy seguido al cine. En primera no nos dejaban y en segunda no había las posibilidades. Luego me caso con un señor que me tiene acá y que hubiera dicho: oye, vete con mis hermanas al cine y yo me quedo con los niños, pues no. $O$ vete tú y yo me quedo con los niños. No había esa posibilidad ni él era tan abierto... por eso, ahora soy felizmente libre.

\section{Conclusiones}

El trabajo con estos entrevistados mayores de sesenta años nos ha permitido elaborar una serie de conclusiones significativas de lo que implicaba, significaba y movilizaba el cine y sus salas en el entorno de una Ciudad de Mé- xico en pleno proceso de modernización urbana y cultural. En este sentido, exponemos las siguientes ideas a debate.

1. Son espectadores que recuerdan más a las salas y al entorno urbano que las películas en sí mismas.

2. Las salas cinematográficas de barrio son feas y pobres, mientras que las del centro eran elegantes y distinguidas pero más caras.

3. La función del intermedio es importante, son muchas las cosas que se hacían: pasear, buscar chicas, comentar, comer, ir al baño.

4. La experiencia de ir con alguien al cine es muy semejante entre los entrevistados: padres en la infancia (o sustitutos tías, tíos, primos); amigos o pareja en la juventud; hijos y pareja en la primera adultez; y prácticamente dejan de asistir conforme avanza la edad.

5. No reconocen el haber sido influenciados por el cine, sea en su forma de ser, pensar o vestir. En los casos en los que se identifica cierta influencia, ésta es secundaria.

6. Son personas con cierta ambigüedad respecto al compromiso político, mientras que la religión la toman como algo dado, sin cuestionamientos.

7. Aparece cierto sesgo machista al momento de elegir u opinar sobre las películas. 
8. La censura resulta significativa para las espectadoras de clase media alta, mientras que no es un tema relevante para los entrevistados de clase media baja, quienes la consideran ajena a su vida, cosa de otros y de políticos.

9. Respecto de las preferencias sobre las películas, parece haber un equilibrio entre las mexicanas y las americanas. Las europeas, especialmente las francesas e italianas, parecen corresponder casi con exclusividad a un consumo de clase media alta. No obstante lo anterior, y si bien en torno al cine mexicano se erige una marcada diferenciación social, todos reconocen la época de oro del cine nacional, especialmente a sus actores y actrices.

10. Más que películas, tramas, historias, recuerdan con cierto atesoramiento emocional a los actores, tanto que no hablan de los personajes, sino de sus nombres propios sin importar la película; casi como si fuera un género: "las películas de Pedro Infante", por ejemplo.

11. Existen diferencias notorias en cuanto a competencias lingüísticas según clase social y nivel de estudios, lo cual deriva en la riqueza del detalle del recuerdo o en el nivel de descripción de las sensibilidades que movilizaron en ellos ciertas películas.
El ir al cine constituye una práctica que describe el momento de agenciamiento juvenil, de apropiación de la ciudad que les permiten construir una cierta identidad generacional al haber sido socializados con ciertos referentes culturales globales (el mainstream cinematográfico) y unos determinados anclajes locales (ser joven en una ciudad latinoamericana a mediados del siglo XX).

Finalmente, confirmando los hallazgos de Allen y Khun, los testimonios nos permiten reconstruir las articulaciones entre las etapas de infancia, juventud y vida adulta de los espectadores, donde el relato biográfico se nutre de la experiencia cinematográfica y urbana. Este ejercicio nos permite reconocer, entre otras cosas, los grados de intensidad del consumo de cine, el significado que adquiere en distintos momentos, la vinculación con la estratificación social, la ciudad que emerge como condición de posibilidad y resultado al mismo tiempo de las prácticas culturales. La trayectoria vital no sólo nos permite reconstruir la experiencia cinematográfica sino cómo esta se articula con el desarrollo tecnológico, la infraestructura urbana, la situación económica y familiar. Esta lectura transversal nos permite identificar cómo va mutando no solo el consumo, si no el sentido del ir al cine a lo largo de la vida de una persona. Y, evidentemente, cómo se ha transformado el ir al cine a lo largo de su historia.

Global Media Journal México 15(28). Enero - junio 2018. Pp. 17-37. 


\section{Referencias bibliográficas}

Allen, R. (2006). Relocating american film history. The 'problem' of the empirical. Cultural Studies; 20(1), 48-88.

Foucault, M. (2008). Topologías. Fractal, 48, 39-62.

García Canclini, N. (1998). Las cuatro ciudades de México. En N. García Canclini (Coord.), Cultura y comunicación en la ciudad de México (pp. 19-39). México: Grijalbo-Universidad Autónoma Metropolitana.

Kuhn, A. (1999). Cinema-going in Britain in the 1930s: Report of a questionnaire survey. Historical Journal of Film, Radio and Television, 19(4), 531-543.

(2004). Heterotopia, heterochronia: place and time in cinema memory. Screen, 45 (2), 106-114.

Meers, P., Biltereyst, D., y Van De Vijver, L. (2010). Metropolitan vs rural cinemagoing in Flanders, 1925-75. Screen, 51(3), 272-280.

Monsiváis, C. (1994). Luneta y Galería. Atmósferas de la capital 1920-1959. México: Departamento del Distrito Federal.

Monsiváis, C. (2000). Aires de familia. Cultura y sociedad en América Latina. Barcelona: Anagrama.

Morley, D. (2008). Medios, modernidad y tecnología. Hacia una teoría interdisciplinaria de la cultura. Barcelona: Gedisa.

Orozco, G. (1996). Televisión y audiencias. Un enfoque cualitativo. Madrid: Ediciones de la Torre.

Ortega y Gasset, J. (1970). La rebelión de las masas. Madrid: Espasa Calpe.

Portillo, M., Urteaga, M., González, Y., Aguilera, O., y Feixa, C. (2012). De la generación X a la generación@. Trazos transicionales e identidades juveniles en América Latina. Última Década, 37, 137-174.

Repoll, J. (2010). Arqueología de los estudios culturales de audiencia. México: Universidad Autónoma de la Ciudad de México.

Rosas Mantecón, A. (2017). Ir al cine. Antropología de los públicos, la ciudad y las pantallas. México: Gedisa.

Staiger, J. (1992). Interpreting films: Studies in the historical reception of American cinema. Princeton, NJ: Princeton University Press.

Staiger, J. (2000). Perverse spectators: The practices of film reception. New York: New York University Press.

Taylor, S., y Bogdan, R. (1987) Introducción a los métodos cualitativos de investigación. Barcelona: Paidós.

Global Media Journal México 15(28). Enero - junio 2018. Pp. 17-37. 